\title{
Proposta de uma Sistemática de Implantação de Troca Rápida de Ferramentas para Indústrias de Forma no Brasil
}

\section{M.Sc. Gustavo Kannenberg \\ M.Sc. José Antônio Valle Antunes Jr.}

Universidade Federal do Rio Grande do Sul - Programa de Pós-Graduação

em Engenharia de Produção

Núcleo de Apoio Tecnológico à Indústria - NUCTEC

Praça Argentina, 09 sala 406 - CEP 90040-020 - Porto Alegre - RS

Palavras chave: troca rápida de ferramenta, produção industrial, flexibilidade

Key-1vords: rapid exchange tooling, industrial production, flexibility

\section{RESUMO}

Existem, atualmente, diversas metodologias de implantação da Troca Rápida de Ferramentas. Entretanto, a sua maioria dedica-se aos aspectos técnicos do processo de otimização da troca de ferramentas. Existe pouca preocupação em desenvolver um ambiente propicio à implantação, praticamente negligenciando aspectos gerenciais e administrativos (ule permitem um planejamento, a curto, médio e longo prazos, de uma implantação global (em toda empresa) da Troca Rápida de Ferramentas. Apresenta-se neste trabalho uma sistemática de implantação de Troea Rápida de Ferramentas cute visá suprir estas deficiências.

A partir de uma combinação conveniente de elementos coincidentes e complementares de diversas metodologias de implantação encontradas na literatura, propõe-se uma sistemática que desenvolval um ambiente favoravel à implantação e que permita um planejamento lógico e sistemático do processo de implantação global da Troca Rápida de Ferramentas.

\section{ABSTRACT}

There are some well known methodologies for Rapid Exchange of Tools. However, most of them emphasize technical aspects of optimizing the exchange of tools. Not much attention has heen paid to the development of an apropriate environment to the implementation of these methalologies, concerning managerial aspects for short. medium and long term planning. This paper presents a methodology that pretends to deal with these constraint.

Based on a mix of coincident and complementary elements from different mathodologies, a systematic approach for developing a favorable environments to the implementation of Rapid Exchange of Tools is proposed. This approach allow's a systematic and logical planning for the global implemantation process of Rapid Exchange of Tools. 


\section{Introdução}

Uma análise das diferentes metodologias cncontradas na literatura demonstra que há pouca preocupação com a criação de um ambientc favorável à implantação de um programa geral de Troca Rápida de Ferramentas para toda a cmpresa. Estas metodologias se precoupam muito com as ctapas técnicas, a respeito dos passos a seguir para que se possa analisar $\mathrm{e}$ solucionar o problema, o que caracleriza uma visão limilada, de curto prazo, com a lógica de resolver o problema de uma máquina em específico. Poucos autores se preocupam com uma clapa de trinamento c conscicntização (HAY, 1992) c com uma análise do processo produtivo como um todo (HALL, 1983).

A partir da análise das melodologias $\mathrm{c}$ tćcnicas encontradas na literatura $\mathrm{c}$ de uma visão crítica do processo de Troca de Ferramentas como um todo, pode-se formular uma sistemática de implantação bastante completa, suprindo-se a necessidade do estabelecimento de diretrizes $\mathrm{e}$ de políticas para definir formas de agir relativamente a diversos tópicos gercnciais, como a aquisição/substituição de cquipamentos $\mathrm{c}$ o projeto de produtos.

Uma metodologia que aborde niveis cstratégicos, táticos c operacionais c que tcnha plancjamento para curto, médio $\mathrm{e}$ longo prazos parece adequada. O nível cstratégico teria por finalidade adequar e preparar o ambicntc para a implantação da Troca Rípida de Ferramentas, cnquanto que o nivel lático se preocuparia $\mathrm{cm}$ formar políticas gerenciais de médio e longo prazos. E é principalmente com relação a estas políticas gercuciais que forma-se uma nova sistemática de implantação de Troca Rápida de Ferramentas. O nivel operacional teria por objetivo apresentar uma seqüência de passos que direcionem o processo de análise $\mathrm{e}$ solução do problema de Troca Rápida de Ferramentas.

\section{Proposta de Sistemática de Implantação}

Desta maneira, pode-se propor uma sistemática de implantação de Trocal Rápida de Ferramentas, que Icve em consideração o médio e longo prazos, c que se preocupe cm criar um ambicntc favorável ao processo de implantação. Esta sistemática consiste, basicamente, dos seguintes passos:

1. Convencimento, conscientização $\mathfrak{c}$ comprometimento da alta administração;

2. Estabelecimento de uma equipe estratćgica;

3. Análise do futuro da planta produtiva:

4. Estabelecimento de políticas de médio c longo prazos, tais como:

5. Definição do equipamento/processo a ser cstudado;

6. Escolla e treinamento das equipes de trabalho;

7. Scparar preparação interna de cxicrna:

8. Simplificação dos passos internos c cxternos:

9. Transferência de passos internos para cxlcrnos 
A seguir apresenta-se um detallamento dos passos cilados anterionmentc.

\section{O Nivel Estratégico}

Este nível visa preparar o ambiente para que um plano de Troca Rápida de Fcrramentas tenha sucesso de implantação, buscando criar uma lógica de análise do sistema produtivo que tenha validade a longo prazo.

\section{Passo 1.Convencimento,conscienti- zação comprometimento da alta administração}

$\mathrm{O}$ apoio da alla administração a um projeto de Troca Rápida de Ferramentas é fundamental, pois, a partir daí, cle terá sua importância reconliccida por toda a cimpresa. Este apoio pode ser fortalccido por umma boa divulgação do projeto $\mathrm{c}$ de seus objetivos cm lodos os niveis da cmpresa. Para lal, é importante que haja uma apresentaçĩo formal do projeto para todos da cmpresa (produção, vendas, marketing, finanças c1c.), principalmente porque a Troca Rápida de Ferramentas tem reflexos cm todos os níveis.

A alta administração tem papel essencial no que diz respeito à liberação de mão-de-obra c de recursos. Ela deve participar do plancjamento global das mudanças $\mathrm{c}$ do acompanlamento $\mathrm{c}$ controle das atividades.

Pode-sc disculir a fundamentação de um projelo de Troca Rápida de Ferramentas coll a alta administraçĩo, bascando-sc cm aspectos tais como: a) a lógica macrocconômica da competição capitalista: uma maior concorrência c mudanças nas exigências do mercado, fazcm necessária a produção de itens mais diversificados c com menores volumes. Tradicionalmente $1 \mathrm{~cm}-\mathrm{se}$ acredilado que a cada vez que a variedade dobra, os custos atmentam $\mathrm{cm}$ tomo de $30 \%$, c que a cada vez cm que o volumc dobra, cstes sc reduzem em torno de $20 \%$ (STALK, 1988). Enlão, como produzir maior variedade $\mathrm{c}$ menor volume sem que os custos aumentem em demasia? Esta resposta os japoneses descobriram, c sua chave ć a redução do 1 cmpo de atravessamento, ou melhor, do tempo necessário desde o pagamento da compra da matéria-prima atć o faturamento do produto acabado, o que inclui tempos de cntrega c transportc, de tramitação dos pedidos (burocracia), tempos de eslocagem etc.

b) a lógica microcconômica: a fim de controlar os custos de produção rclacionados à quantidade c volume, tradicionalmente utiliza-se o chamado lote cconômico de produção (LEF), que define um lamanho mínimo de lole de fabricaç̃̃o ao qual correspondem os menores custos de estocagem e de preparaçĩo de máquimas. No cntanto, cxistc tambćm o lote cconômico de compra (LEC), que muitas vezes pode ser maior do que se fay necessário, exigindo estocagem de matcriais. Os japoneses buscam o ideal de tamanhos de lote de fabricação c de compra iguais (c unilários), c o caminlı para clicgar a isto ć a redução drística dos tempos de preparação de máquinas c a parceria com os fornecedorcs. 
c) a lógica financeira: geralmente a produção não tem condições de atender ao programa de produção semanalmente, isto é, atender primeiramente os pedidos dos clientes para a primeira semana, depois para a segunda, a terceira $\mathrm{c}$ a quarta scmanas. $\mathrm{O}$ que ocorre ć que geralmente se produz todo o programa do mês para um ítem, depois todo o programa do mês para outro ítem, c assim por diante. Isto acaba prejudicando financeiramente a cmpresa, pois o faturamcnto mensal não ć homogêneo: a sua maior parte ocorre no final do mês. Pode-se relacionar a isto $\mathrm{um}$ juro sobre o faturamento, que deve contar a partir do momento $\mathrm{cm}$ que a matéria prima ć comprada. Quanto antes este material for transfonmado c faturado, menores serĩo os juros sobre este faturamento.

A Troca Rápida de Ferramentas permite atender aos pedidos de cada semana (ou até de cada dia) tomando o faluramento mais homogêneo durantc o mês. Alćm disto, com a Troca Rápida de Ferramentas c a sincronização da produção, o lead-lime diminui, reduzindo-sc os custos financeiros sobre os esloques, pois haverá lum giro muito maior de materiais, já que cm pouco tempo estes cntram como matéria-prima c sacm como produtos acabados. Isto lambém reduz o juro sobre o faturamento, pois o objctivo é transformar a matcria-prima cm produto c faturi-lo num mesımo dia.

d) o que se pretende: neste processo procura-se reduzir drasticamente o tempo de preparaçĩo de máquinas. alravés da simplificação do alo físico da preparação, realizando-se mellorias organizacionais c utilizando-sc técnicas de baixo custo relativo. No princípio, as técnicas utilizadas são quase todas de cunho organizacional, cxigindo baixos investimentos. À medida eII que o processo de implantação avança, as técnicas exigem maiores investimentos, devido à necessidade de alterações físicas eur equipamentos c ferramentas. Contudo, os ganhos proporcionados pela Troca Rápida de Ferramentas tendem a cobrir facilmente csics investimentos.

Numa ótica de curto prazo, procura-se libcrar capacidade $\mathrm{cm}$ máquinas gargalo para aumento de produção. A longo prazo, procura-sc fazer com que lodas as máquinas da fábrica tenham condições de realizar uma troca rápida, proporcionando-sc, alćm da redução de custos pela redução de estoques intermediários, uma maior nexibilidade na produção;

c) quem realizarí o traballıo: a lógica de trabalhos cm gnupo é a basc para que se tenlia resullados eficientes e de consenso geral. Para a implantação de um programa de Troca Rápida de Ferramentas parte-se de três niveis de traballo, aos quais correspondem equipes específicas. Tem-se, cกtล̃o:

Equipe cstratégica: é responsável pelo plancjamento de toda a estnutura c formação das políticas de funcionamento (passo 4) do programa de Troca Rápida de Ferramentas para toda a fábrica.

Equipe de raballo: ć a responsável pela anílise, proposição c implemenlação de melhorias possiveis seguindo as regras definidas pela equipe estralcgica c 
bascando-se nas clapas postcriores à scila clapa desta sistemática aqui proposta. Uma cquipe destas ć formulada para atacar um problema específico c depois é desmontada (task-force).

Fcrramentaria c manutenção: são os responsávcis por realizar as alterações físicas necessárias, de acordo com as propostas apresentadas pela equipe de trabalho, da qual fazem parte.

\section{Passo 2. Estabelecimento deuma equipe estratégica}

Esta cquipe constitui-se num grupo responsável pelo plancjamento global do projeto de Troca Rápida de Ferramentas. É cla que vai realizar as clapas iniciais desta sistemática (ctapas 3,4,5 c 6), buscando dar a este projeto condições para um trabalho continuado, seguro $\mathrm{c}$ de longo prazo. Ela tem a função de dar suporte ao processo de implantação, destinar recursos c abrir caminho para que ocorram as modificações necessáriàs.

É composta de umu comitê de pessoas de diferentes qualificações, com autoridade própria para a realização de mudanças. Devem participar pessoas da alta administração, inclusivc o símbolo máximo de poder da cmpresa (dirctor), para realmente gerar o interesse que este traballio de plancjamento merece.

Consultores ou assessores cxternos seriam indicados para providenciar o treinamento adequado, c devem coordenar os traballos, procurando manter a cquipe no rumo certo.

Então, dentro de uma organização típica de uma cmpresa, tem-sc a cquipe cstratćgica formada pelo dirctor, pelo gerente financeiro, pelo gerente industrial, pelos diversos sub-gerentes (engenlaria, produção, manutenção, compras, controle de qualidade etc.) c pelos consultores $\mathrm{c}$ assessores cxternos. É importante ressaltar que esta hierarquia não deve prevalecer dentro da equipe, pois o objetivo ć o traballo cm conjunto, com plena cooperação.

Um dos componentes da cquipe cstratégica deveria participar como um lider nas equipes de trabalho. Este deve ser um facilitador no caso de problemas políticos, burocráticos ou financeiros, que saiba organizar delallies logísticos c traballar com grupos $\mathrm{c}$ individuos. É cle quem vai comandar os trabalhos dentro das politicals de funcionamento estabelecidas no passo 4 desta sistemática. Este líder deveria participar do maior número de equipes possivel. Elc seria o maior cncarregado no processo, um representante do projeto de implantação da Troca Rápida de Ferramentas em loda cmpresa.

Esta cquipe est ratégica deve saber como ć o processo de implantação da Troca Rápida de Ferramentas, inclusive as tćcnicas utilizadas para tal, a fim de que possam avaliar c plancjar com clareza c scgurança a implantação $\mathrm{cm}$ sua cmpresil. Para isto faz-sc necessário um treinamento específico, como ć indicado no passo 4 (cslabelecimento de políticas de médio c longo prazos). 


\section{Passo 3. Análise do futuro da planta produtiva}

Uma análise do futuro da planta produtiva é necessária para que esforços de redução de tempos de troca de ferramentas não scjam desperdiçados por screm mal plancjados c dirccionados. Para isto, torna-se importante a definição de algumas políticas de attação, sendo incvitável a ligação deste passo 3 com o passo 4 da sistemática geral, onde se propõc a necessidade de discussão de diversas políticas de plançamento $\mathrm{e}$ de atuação.

A verificação e a garantia de que planos de modificações cm processos c produtos nĩo prejudiquem ou gerem o desperdício de csforços na Troca Rápida de Ferramentas é tarefa da gerência. e deve fazer parte do scu trabalho rotinciro. Prever estes planos não ć larcfa rácil, mas ć de boa ajuda a revisão de que peças e produtos cstão destimados a que processos, ou seja, procurar definir a possibilidade de criar fábricas focalizadas ou células de produção.

A realização de uma análise destas lambém demonstra que a gerência $c$ a administração cstão cnvolvidas c intcressadas no processo, o que complementa a primcira clapa de comprometimento da alta gerência

Alguns pontos que devem ser levados em consideração nesta análise são:

- altcrações cm processos: geralmente comprecndem a compra ou venda de cquipamentos, ou modificações tćcnicas destes. Estas alterações devem ser previstas c plancjadas, integrando-se ao projeto de Troca Rápida de Ferramentas, pois não sc pode perder esforços na alteração de um equipamento ou processo que vai ser eliminado. Sugere-sc levar $\mathrm{cm}$ consideração as caracteristicas apresentadas na política de aquisição c substituição de equipamentos do passo 4;

- alterações em pessoal: cste ć um fator primordial no projeto, pois são as pessoas que vão realizar os"trabalhos. Não sc pode perder esforços (trcinamento, motivação, cnvolvimento) com pessoas que podem vir a ser desligadas da empresa, que não quciram ou não tenham condições de participar do processo, on que não esıcjam convencidas de sua importancia, principalmente pelo efeito negativo que recali sobre os outros interessados. Torna-se importante o indice de rotatividade de pessoal da compresa:

- alterações em produtos: a criação de novos produtos ou a alteração de produtos já cxistentes podem afetar diretamente a Troca Rápida de Ferramenlas e, por isso, também devem integrar-sc ao projeto de implantação da Troca Rápida de Fcrramentas.

\section{O Nível Tático}

Aqui se procura analisar e propor políticas gerenciais $\mathrm{e}$ de atuação gerais, que dêcm ao projeto de implantação global da Troca Rápida de Ferramenlas uma caracteristica de validade de médio e longo prazo, de tal forma que tudo seja plancjado antecipadamentc, cvitando-sc imprevistos c problemas de definiçĩo de objetivos c 
responsabilidades. São basicamente políticas que permitcm o planejamento $\mathrm{c}$ direcionam a atuação de forma concisa. $O$ nivel tático consiste do passo 4 desta sistemática, de cstabelecimento de políticas de médio c longo prazos.

\section{Passo 4. Estabelecimento de políticas de médio e longo prazos}

Estas políticas são necessárias para viabilizar um projeto de Troca Rápida de Ferramentas a médio c longo prazo. Cada cmpresa tem uma forma diferente de trabalhar e uma estrutura de recursos lumanos característica. Portanto, cstas políticas podem ter variações de caso a caso, scndo que o procedimento mais indicado é o desenvolvimento de políticas próprias, adaptadas à realidade de cada cmpresa. Os assuntos abordados por cada uma deslas politicas sĩo discutidos a seguir:

\section{a) aquisição e substituição de cquipamentos}

Normalmente, a aquisição de novas máquinas dá-se na busca de uma maior produtividade $c$ maior qualidade, não levando $\mathrm{cm}$ consideraçĩo a Troca Rápida de Ferramentas. A compra de equipamentos geralmente busca aumento de capacidade produtiva. Uma vez que um bom cstudo $\mathrm{c}$ a implantação da redução de setup libera capacidade, pode-se climinar a necessidade de compra de equipamentos.

Nem scmpre a aquisição de cquipamentos novos surtirá o efeito desçado com relação à Troca Rápida de Fcrramcntas, pois estes equipamentos geralmente são idealizados para atender aos mais diversos clientes. Como cada clientc tem necessidades específicas no que diz respeito à Troca Rápida de Ferramentas, cle tcrá de adaptar este cquipamento para suas necessidades $\mathrm{c}$ suas atividades. O ideal seria produzir ou alterar seu próprio equipamento.

Segundo Hayes (1990), pelo menos $50 \%$ dos equipamentos de cmpresas japonesas são desenvolvidos dentro das próprias fábricas, pelos seus próprios cngenheiros c operadores, c aproximadamente $40 \%$ do P\&D se destinam ao aperfeiçoamento de máquinas c processos. Estes cquipamentos c dispositivos são dirigidos às próprias necessidades da empresa, e têm custos c prazos de cutrega menores. Os cuslos são menores porque a máquina pode ser mais simples, menos robusta, dedicada somente a decrminadas necessidades; não são máquinas de utilidade geral. Seus custos também não incluem o lucro do fabricante c nem seus custos de incficiência, embutidos nos preços. Também não ficam sujeitos aos preços de mercado, variáveis com a situląĩo cm que este se cncontra.

Percebe-se a importância da análise do equipamento sob ponto-de-vista da Troca Rápida de Ferramentas, uma vez que se identificam alterações necessúrias $\mathrm{c}$ pontos potenciais de melhorias em equipamentos $\mathrm{c}$ procedimentos.

Uma vez decidida a compra de novos equipamentos. deve-se procurar comprar cquipamentos já adaplados à Troca Rápida de Ferramentas. A compra de cquipamentos 
novos pode, tambćm, levar em conta a necessidade de facilitar o selup via simplificação dos equipamentos, isto ć, pela substiluição de cquipamentos complexos por células de equipamentos mais simples que realizem as mesmas operações.

A troca de ferramenlas cin cquipanculos complexos geralmente exige pessoal cspecializado c lcva muito tempo. Estes equipamentos também são mais difíccis de serem modificados fisicamente para uma Troca Rápida de Ferramentas.

Substituir equipamentos complexos por cćlulas de cquipamentos mais simples que realizem as mesmas funções pode ser uma soluçĩo, pois equipamentos simples, alćm de cxigirem manutcnção simplificada, são Inais fáceis de converter para a Troca Rápida de Ferramentas. Estes equipamentos poderiam ser mais facilmente convertidos (pcla própria compresa) para uma Troca Rápida de Ferramentas, devido à simplificaçĩo do processo de preparação. Esta substituiç̃o deve scr muito bcm analisada. em funçĩo do tipo de peças e quantidades fabricadas, $c$ do tipo de máquina cm questão.

Na compra de equipamentos deve-se procurar um certo nível de padronização, adquirindo-os do mesmo fabricante dos equipamentos já cxistentes na cmpresa. A prática de padronização de equipamentos apresenta vantagens lais como:

- redu\%-se consideravelunente o processo de aprendizado do operário c a manutenção torna-sc mais simples, principalmente pelo fato do princípio de funcionamento das máquinas ser o mesıo. O mecânico ou operador só precisa conhecer os princípios básicos de uma desias máquinas para sabcr como funcionam as outras;

- reduz-se a necessidade de pessoal cspocializadocmdiversos cquipamentos difcrentes (mantenção c preparação);

- reduz-se a quantidade (variedade) de ferramenlas, dispositivos c peças de reposição;

- no que diz respeito à Troca Rápida de Ferramentas, soluçôcs c dispositivos criados para decrminada máquina podem ser usados ou adaplados sem problemas às demais;

- a padronização de ferramentas c dispositivos toma-sc mais simples, assim como a criaçĩo de padrõcs ou roteiros de procedimentos e sua implantação, já que os equipamentos são parccidos;

- têm-sc potencial de barganha com o fornecedor de máquinas. pois a cmpresal acaba se tormando $\mathbf{1 m}$ clicutc especial, que só adquire cquipamentos deste fornecedor. Pode-se obler facilidades de pagamento ou de assistência c manutenção.

Alé certo ponto, pode-se implementara Troca Rápida de Ferramenlas sem se preocupar com este tipo de padronização. $\mathrm{O}$ que ocorre ć que a falla de padromização torma as atividades de preparação extcrma bastante complicadas. muitas vezes cxigindo a utilização de diversas listas de 
matcriais c procedimentos, uma para cada conjunto de máquina/ferramenta/produto. Esta grande quantidade de listas c labclas podem fazer com que sua utilização não seja levada a cabo na prática, já que cm muitas indústrias os traballuadores têm pouca formação teórica (FLEURY, 1992) c/ou tem aversão à burocracia. A padronização de cquipamentos simplifica c facilita o trabalho dos opcradores.

\section{b) projeto de produtos visando à Troca Rápida de Ferramentas}

As condições de mercado exigem hoje grande variedade de produtos, cada vez mais personalizados c adequados às cxigências e necessidades do consumidor. Ao procurar atender a cssa grande variedade de produtos, o sistema produtivo de uma empresa tende a se complicar muito, pois aumentam $\mathrm{cm}$ número $\mathrm{e}$ complexidade os componentes c processos a serem execulados. O número de fornecedores $\mathrm{c}$ peças compradas cresce muito, faz-sc necessária a aquisição de novas máqquinas $\mathrm{c}$ a contratação de mais pessoal, a burocracia acaba tornando-se cnome clc. O sistema entra cm colapso se não puder suportar esse incremento nos custos $\mathrm{cm}$ geral. No momento em que a varicdade de produtos aumenta, se faz necessária a Troca Rápida de Fcrramentas para viabilizar a rápida mudança da fabricaçĩo de um produto para outro.

Mclhor do que reduzir o tempo de preparação é eliminar a necessidade de realizar preparaçõcs. Pode-se abolir por si mesma a troca de ferramentas. usando o descnho do produto e mesmas peças para diferentes produtos (padronização de componentes) ou produzindo diferentes peças ao mesmo $\mathrm{tempo} \mathrm{cm}$ várias máquinas, cm paralclo.

A padronização de componentes reduz a quantidade/variedade de ferramental cxistentc, pois o número c diversidade de componentes diminui. Tem-se menos produtos a serem fabricados por máquina, reduzindo-se o número total de preparações necessárias. Fabrica-se maior quantidade de um menor número de componentes, o que reduz a complexidade $\mathrm{c}$ os custos globais do sisicma (baseado cm STALK. 1988). Cada componente $1 \mathrm{~cm}$ códigos $\mathrm{c}$ componentes de custo diferenciados, o mesmo ocorrendo com o ferramental que utiliza. Existe a necessidade de controle $\mathrm{e}$ manipulaçĩo de cada um destes ítens, c a redução de sua variedade contribui muito para a simplificação do sistema.

A grande tática para viabilizar grandes diversificações de produtos, ao lado da Troca Rápida de Ferramentas. é a padronização de componentes e produtos. Isto significa trabalhar com produtos modulares, projelados de tal forma que sejam tolalmente diversificados, mas que utilizem componentes e processos idênticos. Fabrica-sc uma gama limitada de componentes que adequadamente montados c combinados produ\%cm produtos finais diferentes. Isto reduz a quantidade de processos e componentes cnvolvidos na fabricação de grande varicdade de produtos.

No limitc, com a padronização dc produtos, ou scjal. com a fabricação de 
componentes básicos padronizados que scrão utilizados $\mathrm{cm}$ difcrentes produtos finais, o tempo de troca de ferramentas pode reduzir-se a zero, havendo a possibilidade de não se trocar ferramenta alguma. Haverá uma menor quantidade de ferramental $\mathrm{c}$ uma grande simplificação do sistema produtivo.

Podem ocorrer casos em que o conjunto do mix de produção csicja mal plancjado c muitos esforços no sentido da Troca Rápida de Ferramentas podem ser reduzidos se houver um bom estudo de padronização.

Por outro lado, existe a possibilidade de climinar o setup pela fabricação $\mathrm{cm}$ paralclo. Quando sc produz num maior número de máquinas, reduz-sc a variedade de peças por máquina, reduzindo-se o número de preparações em cada uma delas. No entanto, percebe-sc que csta ć uma solução de custo bastantc clcvado, pois cxigc a aquisição de novos cquipamentos.

O projeto de novos produtos também precisa levar cm collsideração as fcramentas c máquinas que os produzcm, de tal forma que se possa icr ferramentas $\mathrm{c}$ equipamentos nos padrões adequados para a Troca Rápida de Ferramentas. Oı seja, deve haver uma preocupação com funções, formas c dimensões de tal forma que se tcnha condições de utilizar os padrões já cxistentes para a Troca Rápida de Ferramentas, ou que propiciem condições para a utilização de novos padrões, lambém voltados para a Troca Rápida de Fcramentas.

c) procedimentos gerais de

\section{priorização ao ataçuc}

A definição de equipamentos, ferramentas e produtos a serem alterados primciramente na busca da Troca Rápida de Ferramcnlas ć um dos pontos mais importantes para que se obtenham resultados eficientes $\mathrm{em}$ pouco tempo.

O eixo central desta política baseia-sc no Gerenciamento das Restrições (GDR, TOC - Theory of Constraints ou OPT Optimized Prroduction Technologv (GOLDRATT, 1992)). Segundo csta tcoria, cxisıcm máquinas gargalo que limitam a produção de toda a planta produtiva, c melhorias realizadas nestes equipamentos se refletem cm todo o sistema. A identificação dos gargalos $\mathrm{c}$ a aplicação da Troca Rápida de Ferramentas como forma de reduzí-los (ANTUNES \& RODRIGUES, 1993), consistem numa eficiente forma de tomar o sislcma produtivo mais ágil c administrá-lo adequadamentc.

A prioridade para alterações rumo à Troca Rápida de Forramentas são, cnlão, as máquinas gargalo. Com isto cvita-sc a possibilidade de desperdiçar esforços c investimentos cm máquinas que não irão contribuir eficicntemente para o ólimo global do sistema de produção. É importante ressaltar que os cquipamentos $\mathrm{c}$ ferramentas que necessitam modificações fisicas ficam parados por certo período de tempo, mas as melhorias feitas apresentam resultados a longo prazo durante toda a vida do equipamento, c mesmo cm curto prazo, porque a Trequîencial de trocas aumenta muito.

É importante ressallar que, 
normalmente, boas reduções de tempos de setup podem ser obtidas apenas com mudanças organizacionais $e$ comportamentais, que não exigem alterações físicas $\mathrm{em}$ máquinas $\mathrm{e}$ ferramentas. Isto faz com que os custos de desperdiçar esforços em equipamentos não gargalos não sejam tão altos, podendo-se, então, em épocas de baixa produção ou de alta ociosidade, até traballar indiscriminadamente no maior número de máquinas possivel. Contudo, a abordagem da TOC sempre é válida. Para a escolha de prioridades cxistem diversos outros fatores que podem ser considerados, como:

- experiência (know-how) cmalterações físicas para a Troca Rápida de Ferramentas. Quando se tem pessoal capacitado, experiente em realizar alterações fisicas em equipamentos e ferramentas, não há uma maior preocupação com a complexidade dos objetos em estudo, nem dos processos de troca de ferramentas. Mas quando não se tem experiência, deve haver uma preocupação $\mathrm{cm}$ iniciar os trabalhos com equipamentos mais simples, pois isto trará experiência básica para o desenvolvimento com máquinas mais complexas, já que muitas vezes trabalhos complexos compreendem os passos de trabalhos mais simples;

- importância do equipamento e das ferramentas para a empresa: geralmente equipamentos e ferramentas importantes são aqueles que processam a maior quantidade de produtos ou os que processam os produtos mais caros $\mathrm{e}$ rentáveis da cmpresa (scgundo a TOC são os gargalos). Nestes casos uma Troca Rápida de Ferramentas e uma grande flexibilidade de troca entre produtos são altamente desejáveis. Isto talvez minimize a preocupação com a disponibilidade destes equipamentos ou ferramentais, já que os ganhos são proporcionalmente maiores;

- disponibilidade do equipamento e do ferramental: a realização de modificações em máquinas e ferramentas fica, muitas vezes, sujeita à disponibilidade destes. Sugere-se levar em consideração a ociosidade de máquinas em épocas de baixa produção, aproveitando-se estes períodos para a realização de alterações físicas também em ferramentas. A parada de máquinas $\mathrm{e}$ ferramentas exige uma análise mais detalhada da relação custo/beneficio, o que depende basicamente da importância do equipamento para a empresa (deve-se procurar modificar estas máquinas e ferramentas fora do horário de trabalho, em feriados e fins de semana);

- projetos piloto: em casos onde a resistência à liberação de equipamentos for muito forte, pode-se partir para o desenvolvimento em náquinas piloto, a fim de convencer e provar que o que se propõe é factivel e produz resultados. Entretanto, se possível, deve-se selecionar um processo que tenha impacto direto sobre clientes externos, com o qual a maioria dos gerentes esteja preocupada, que esteja numa área ou num setor onde se tenha a cooperação de gerentes, 
supervisores c operadores, c que scja visivel na organização. Tudo isto para que os impactos dos resultados sejam percebidos também fora deste sctor ou departamento.

\section{d) definição de metas para planejamento}

É importante que se coloquem algumas metas, objetivos c limitações ao projeto de implantação de Troca Rápida de Ferramentas, como:

- Implantação global, no maior número possivel de equipamentos da cmpresa, seguindo-sc as políticas de atuação existentes;

- Objelivos claros de redução de tcmpos: a definição de objetivos ambiciosos, como a redução de $80 \%$ do tempo de preparação cm cada máquina, ou ainda, alcançar limiles abaixo de 10 minutos cm todas as máquinas da fábrica (SMED, SHINGO (1985)), representam a detcrminação $c$ a intenção de realmente fazer e alcançar o máximo possível;

- Prazos de cxecução: a definição de limiles de tempo para a execução de melhorias facilita o controle do processo, permitindo uma mellor cobrança de resultados;

- Cuslos c recursos: ć necessária a definição de limites financeiros. dentro dos quais deve ser desenvolvida a maioria das alterações $\mathrm{c}$ melhorias. Proposlas de melhorias de custo supcrior ao cstipulado necessilam de aprovação especial;

- Definição de um fundo financeiro especial para financiar investimentose permitir a realização de testes de algumas idéias propostas para cada um dos equipamentos a ser trabalhado: isto permite controlar melhor estes investimcntos, pois haverá condições de avaliar com maior precisão o custo para alıcração de certo equipamento $\mathrm{c}$ a certcza de que cslas alterações serão bem planejadas, pois os recursos são cscassos e devem ser bem administrados. Também é uma forma de facilitar a realização prática da Troca Rápida de Ferramentas, pela climinação de burocracias desnecessárias, e representa também o cnvolvimento $\mathrm{e}$ a confiança da alta administração no processo (o que reforça o passo 1 ).

c) construção padronizada de dispositivos, ferramentas e máquinas

A construção padronizada refere-se a dois processos distintos: 1) a fabricação padronizada de novos dispositivos, ferramentas $\mathrm{c}$ máquinas $\mathrm{c} 2$ ) a padronização de dispositivos, ferramentas e equipamentos já cxistentes. Para os componentes (ou clementos) já cxistentes, deve haver uma política de priorizaçĩo, como já foi discutido anteriormentc. Para os novos projetos, devem ser idealizados padrõcs especiais, que levem $\mathrm{cm}$ consideração a Troca Rápida de Ferramentas.

Uma política de constnıção padronizada 
para a Troca Rápida de Ferramentas deve direcionar os esforços para a padronização de função, c não de forma (baseado em SHINGO, 1985).

Na padronização de funções padroniza-se somente aquelas partes cujas funções são necessárias sob ponto-de-vista de troca de ferramentas. Deve ocorrer uma análise das funções de cada clemento, $\mathrm{c}$ a troca de um minimo de elementos quando da mudança de produto. Por excmplo, $\mathrm{cm}$ um braço mecânico só deve-se altcrar sua garra, de acordo com o produto. Não lú sentido na troca de todo o braço. Todas as garras devem ser padronizadas para que sirvam no mesmo braço mecânico, isto ć, clas devem ter padronizadas somente as partes de fixação ao braço. A padronização de formas nĩo é recomendada pois ocorre desperdicio de materiais devido ao tamanho por vezes desnecessário de ferramentas $\mathrm{c}$ matrizes, gerando com isto um aumento de custos.

A definição de quais parıes padronizar, c em que dimensões, depende do cquipamento $\mathrm{c}$ das características próprias dos produtos c ferramentas utilizados, provavelmente só podendo ser definidos quando houver conhecimento suficiente do processo, ou seja, quando se estiver realizando a análise de climinação de ajustes e tansferencia de tarefas intentas para cxtcrias.

Não deve-se nunca esquecer as características de segurança necessárias cm projelos mecânicos. para não danificar equipamentos ou ferramentas $\mathrm{c} n \mathrm{~cm}$ colocar cm risco as pessoas que trabalham nos mesmos.

\section{f) disponibilidade da ferramentaria e da manutenção}

Um dos maiores problemas que a Troca Rápida de Ferramentas enfrenta no momento da realização de modificações técnicas, alćm da resistência à utilização de novos sistemas simplificados $c$ descnvolvidos pela própria cmpresa, ć a disponibilidade de pessoal e cquipamentos que tenham capacidade de executar estas alterações. Normalmente, ferramentciros, mecânicos, soldadores e seus cquipamentos estão muito ocupados realizando reparos de máquinas $\mathrm{c}$ ferramentas $\mathrm{e}$ desenvolvendo novos dispositivos ou ferramentas.

Esla questão se resolve pela definição de políticas de atuação $\mathrm{c}$ de prioridade dos traballos, sendo muitas vezes importante a intervenção da gerência para confimmar a importância do processo de Troca Rápida de Ferramentas.

\section{g) educação e treinamento}

O objetivo principal desta política é estabelecer condições para a implantação global da Troca Rápida de Ferramentas $\mathrm{c}$ para o repasse desta metodologia de implantação. Ou seja, procura-se fazer com que hạja uma divulgaçĩo do trabalho por toda a cmpresa c com que as pessoas mais cnvolvidas conheçam os objetivos do trabalho, cntendam a metodologia $\mathrm{c}$ as técnicas cxistentes e sabam como utilizí-las, de forma que clas tenham condições de implementar o sistema por toda a fábrica. Neste ponto ć importante que 
se observe a compatibilidade da metodologia com o nivel educacional vigente cm cada nível hierárquico da empresa.

Esta politica abrange, basicamente, três niveis hierárquicos na empresa: a alta gerência, a média gerência e o pessoal de chão-de-fábrica. O repasse deve ser realizado através de seminários e cursos específicos de treinamento, com o uso de uma linguagem adequada a cada nível, mesmo porque cada nível tem interessc cspecífico $\mathrm{cm}$ determinadas características da Troca Rápida de Ferramentas e em certas fases da sistemática. É precisamente por isto que esta sistemática se divide em três níveis, um estratégico, um tático $\mathrm{c}$ um operacional.

Aspectos estratégicos e administrativos devem ser apresentados à alta gerência numa linguagern mais financeira e menos técnica, baseada em dados e fatos, e devem fazer parte também do primeiro passo desta sistemática (convencimento e conscientização da alta administração).

Os aspectos táticos dizem respeito à média gerência, que é a que tradicionalmente tem maior resistência à mudanças (FLEURY, 1992). Eles devem ficar a par de todos os tópicos, desde os administrativos até os operacionais, isto é, devem ficar sabendo porquê e como atingir uma Troca Rápida de Ferramentas, justamente para que percebam a potencialidade do processo.

Geralmente, quando se apresentam as técnicas normalmente utilizadas, surgem afirmações do tipo "não funciona, não pode ser fcito, não se aplica ao nosso caso, nós somos diferentes etc.". Para combater estas afirmações e crenças, deve-se demonstrar casos práticos de sucesso existentes, através de vídeos e visitas a empresas. No caso de resistências muito acirradas, sugere-se que a alta gerência cnvolva-se enérgicamente no processo.

Aspectos operacionais são apresentados ao pessoal de chão-de-fábrica, que deve passar a compreeender o método que será aplicado c ficar a par das técnicas normalmente utilizadas. Deve ficar claro que a proposição de novas técnicas $c$ soluções para a Troca Rápida de Ferramentas sempre é possivel, já que cada equipamento, processo e ferramental é diferente um do outro (cada caso ć um caso).

Constata-se, entretanto, que a mão-de-obra direta das empresas brasileiras tem baixo nível educacional (FLEURY, 1992), o que exige a formulação de apostilas simplificadas, com linguagem adequada, com muitos exemplos práticos, esquemas e figuras. Muitas pessoas têm dificuldades em entender gráficos $\mathrm{e}$ desenhos técnicos, sendo muito indicada a utilização de vídeo-tape e de protótipos em escala de sistemas de troca rápida, além da realização de visitas a diversas empresas onde os resultados da Troca Rápida de Ferramentas já estejam consolidados.

A gravação em vídeo tem um grande papel no treinamento e na motivação de pessoas, principalmente no caso da Troca Rápida de Ferramentas. Sempre procura-se gravar as situações atuais de funcionamento 
e de traballo, a fim de analisá-las $\mathrm{cm}$ conjunto com as equipes, observando-se pontos fortes e fracos do sistema. Após a impantação da Troca Rápida de Ferramentas realiza-se nova filmagem, de forma que se possa comparar o sistema antigo e o atual imediatamente. Estas gravações podem ser utilizadas no treinamento de novas equipes, sendo que este é facilitado se houver um ciemplo da própria empresa.

A utilização de protótipos em escala permite que se demonsire na prática as situações antes c após a Troca Rápida de Fcramcntas, alcm de auxiliar no entendimento do processo e das técnicas que podem ser aplicadas. Há uma comprovação concrela, in loco, de que o principio funciona muito bem.

Em casos onde o nivel de instnıção é muito baixo, nem vale a pena tentar explicar técnicas de análise para auxílio no desenvolvimento de novas soluções para a troca de ferramentas. É mais eficiente passar a fase de análise para pessoas mais capacitadas, mas os trabalhadores não devem ser deixados de lado $\mathrm{em}$ hipótese alguma. São os operadores que sabem utilizar e conhecem bem as características dos equipamentos $\mathrm{c}$ dos processos a serem estudados e alterados. Eles podem ter várias contribuições a dar, embora possam não saber apresentá-las de um ponto-de-vista formal.

Nas primeiras fases da implantação pode ser interessante a participação de um consultor ou assessor extemo especializado para a claboração do matcrial adequado e para a apresentação de todos os tópicos relevantes da Troca Rápida de Ferramentas. Ele scria o encarregado de providenciar o treinamento.

Cabe ainda colocar que um dos objetivos da disseminação da Troca Rápida de Ferramentas por toda empresa é permitir a multifuncionalidade dos operadores. Muitos operadores sequer participam do processo de preparação de máquinas, que é delegado tolalmente ao especialista $\mathrm{cm}$ setup. Neste ponto, toma-se muito importante a colaboração destes cspecialistas no treinamento dos operadores para a tarefa de sellup. O processo de transferência de responsabilidades pode ser gradual, onde o operador inicia auxiliando na troca, envolvendo-sc e conhecendo o processo de preparação, e termina por realizá-la independentemente.

\section{h) formação das equipes de trabalho}

Este lipo de equipe (lask-force) ć organizada para atacar especificamente uma determinada máquina $\mathrm{e}$, depois de resolvido o problema, ela é desmontada. Para cada equipamento em específico define-se uma equipe de trabalho adequada.

Uma equipe de trabalho deve ter certa autonomia para desenvolver suas idéias, 0 que deve, em parte, ser proporcionado pela alta gerência através da liberação de um fundo financeiro especial c pela participação efetiva do lider da equipe, participante também da equipe cstratégica (o que reforça mais ainda a primeira etapa desta sistemática, a de envolvimento da alta gerência). O objetivo desta autonomia ć 
agilizar o processo de mudanças e cvitar atrasos devido à burocracia cà problemas políticos dentro da cmpresa.

Nestc scntido, sugerc-sc a comunicação formal à cquipe, por parte da gerência, das limitações desta autonomia. Deve ficar claro o que pode c o que não pode ser realizado independentemente por esta equipc.

Estas equipes de trabalho devem ser formadas pelos opcradores c pelo pessoal cspecializado na preparação das máquinas. pois são cles que conliecem bem os equipamentos c processos a screm csludados.

As altcrações físicas em equipamentos c ferramentas são, gcralmente, rcalizadas pela ferramentaria c pela manutenção, devendo cste pessoal, obrigatoriamente, participar do processo. No caso de não haver condições de realizar as alterações físicas de equipamentos na própria cmpresa, sugere-sc que os cncarregados da cmpresa sub-contratada para realizar o serviço também participem do processo.

É importantc a participação de uı líder, facilitador para problcmas politicos, burocráticos ou financciros. Estc membro deveria ser, preferencialmente, componente da equipe estratégica. como discutido anteriomente na clapa de formação desta cquipe. Ele seria o representante da alta administraçĩo responsável pela participaç̃o efcliva no projeto de implantação da Troca Rápida de Ferramentas.
Sugerc-se que cngenheiros c projetistas participem como staff de apoio. Contudo, devem participar mais efetivamente quando ocorrerem casos onde se fizerem necessárias modificações técnicas $\mathrm{cm}$ cquipamentos, ferramentas c produtos, principalmente para garantir a segurança do sistema. Sua participação deve ser ampla, mas nõo antoritária.

Quando há pouca experiência do gnupo em relação à Troca Rápida de Fcrramentas, ć interessantc a presença de um guia, com cxperiência na condução deste tipo de processo de implantação. Ele deve dirigir os trabalhos c manter a cquipe num numo adcquado, alćm de providenciar o treinamento necessário. Portanto, consultores $\mathrm{c}$ assessores cxternos lambém podem fazer parte do staff de apoio.

Cada empresa $t \mathrm{~cm}$ características distintas de recursos humanos, c a cscolla dos componentes das equipes varia muito com as caracteristicas de cultura c conhecimento de cada componente. Entretanto, o fator principal que determina a melhor composição da equipe ć a motivação, o envolvimento, a relação com o processo de troca, a capacidade c a complementaridade de cada componente. Deve haver cm cada um a delerminação de atingir os objetivos propostos, atravćs de um trabalho sério de análise e modificação do processo de troca de ferramentas.

Pcrcebc-se que, $\mathrm{cm}$ grande parte dos casos. alguns membros desta equipe scrão fixos para todo o processo global de implantação, c outros scrão variávcis. Ficam fixos, normalmente, o staff de apoio. 
o líder c o pessoal da manutenção $c$ da ferramentaria. São variáveis os operadores de máquina e os especialistas $\mathrm{cm}$ setup.

Como estas equipes de trabalho são momentâneas, tambćm tcm importância a definição de um ritmo de descnvolvimento do trabalho. Uma dedicação mais intensa deve ser dada à fase de análise do processo de setup, pois é deste que dependem as idćias c propostas de melhorias. A discussão de aspectos ligados à padronização também merecem maior dedicação.

Certamente, no que diz respeito à Troca Rápida de Ferramentas, a dedicação cxclusiva ć mais intcressante, pois proporciona resultados mais imediatos, mas implica na retirada de pessoal de suas tarefas diárias. É bastante interessante a idéia de inclusão de reuniões diárias sobre o assunto, tornando a preocupação com a Troca Rápida de Ferramentas uma tarefa do cotidiano. Mas, geralmente, reuniões ที̃o têm a duração necessária para se tratar de certos aspectos da Troca Rápida de Ferramentas, c mais tempo deve ser-lhes dedicado.

Pode-se adequar o ritmo de traballho com as condições de alta ou baixa produção da fábrica. Se houver baixa produção deve-se aproveitar a ociosidade dos operadores para trabalhos intcusivos $\mathrm{cm}$ busca da melhoria do sistema de preparação de máquinas. Sc houver alta produção, uma das formas apresentadas anteriormente deve ser adotada. É importante, no cntanto, que haja um trabalho continuado para a implantação da Troca Rápida de Ferramentas.

\section{i) normas de seguurança e risco}

A preocupação com a segurança do pessoal, de equipamentos, de ferramentas $\mathrm{c}$ de materiais deve ser uma constante no projelo de Troca Rápida de Ferramentas. É aqui que se incluem as responsabilidades dos engenheiros c projetistas $c$ do coordenador das equipes.

Existem basicamente duas fases onde a segurança se torna crítica: uma $\mathrm{cm}$ regime transilório (testes) c uma em regime permanente. Quando se implementa um novo procedimento, um novo sistema ou alguma modificação física no processo, cxiste uma fase transitória, de testes, que procura verificar a segurança do que foi implementado.

Uma vez aprovada a fase de testes, deve haver IIII controle rigoroso $\mathrm{cm}$ regime permanente, onde devem ser realizadas inspeções periódicas, até que se tenha total segurança no processo. No início, devem haver revisões em curtos intervalos de tempo, sendo estes intervalos cada vez mais longos à medida cm que o sistema fica mais tempo cm funcionamento c se demonstra mais seguro.

É importante que se observe a vida útil de novos dispositivos e ferramentais descnvolvidos. Com a utilização mais frequiente pode haver a necessidade $\mathrm{de}$ substiluição periódica destes clementos.

\section{j) normas de documentação}

É Imuito importante que se tenha todo o processo de implanlação bem documentado. 
Sugere-se a elaboração sistemática de atas das reuniões contendo, além dos assuntos discutidos, as idéias propostas, seus prazos de implantação e as responsabilidades atribuídas a cada pessoa. Deve haver, também, um controle financeiro durante o processo de implantação.

Uma das técnicas utilizadas para análise do processo é a filmagem em vídeo. É importante que se tenha arquivadas as filmagens dos processos anteriores e posteriores à Troca Rápida de Ferramentas. A memória mantida em vídeos é ponto mais importante do processo de documentação, pois estes deverão servir para o treinamento posterior de outros grupos c equipes.

Provavelmentc, as cmpresas que venham a implantar a Troca Rápida de Ferramentas já tenham normas estabelecidas para a documentação de reuniões, mas vale à pena ressaltar a importância de se ter atas atualizadas, com todos os tópicos discutidos c todas as responsabilidades que foram atribuidas a cada componente da equipe. Isto permite avaliar o andamento do processo e serve como mecanismo efetivo no sentido do cumprimento de prazos através do comprometimento do membro perante os demais componentes da equipe.

Sugere-se a manutenção de uma base de dados dos tempos de troca de ferramentas, de forma que se possa acompanhar a evolução do processo $\mathrm{cm}$ cada cquipamento c globamente

\section{O Nível Operacional}

Neste nivel, procura-se estabelecer uma metodologia de trabalho, que direcione os esforços para que se atinja de forma eficiente e segura a Troca Rápida de Ferramentas. Esta metodologia deve ser aplicada para cada equipamento que se procurar melhorar. As prioridades de ataque já seriam determinadas anteriormente, dentro das políticas definidas no passo 4 .

\section{Passo 5. Definição do equipamento/} processo a ser estudado

Estc passo deve seguir a política de priorização ao ataque definida no passo 4.c desta sistemática. É importante que se trabalhe dentro desta política, para que os esforços empreendidos não sejam mal direcionados. Tanto neste passo 5 quanto no passo 4.c é importante fazer uso da técnica de Gerenciamento das Restrições para melhor definir o equipamento/processo a ser estudado.

Passo 6. Escolha e treinamento das equipes de trabalho

As equipes de trabalho são diferentes para cada equipamento, já que estes são diferentes uns dos outros c os seus operadores não são os mesmos, tendo especialidades diferentes. A politica de formação da equipe de trabalho já discutida anterionmente (passo 4.h) ajuda a direcionar a escolha dos componentes, mas não se pode dizer que esta formação seja rígida $\mathrm{c}$ que se deva seguir à risca esta política.

Uma politica de treinamento como a proposta anterionmente (passo $4 . \mathrm{g}$ ) permitc apresentar 0 assunto, envolver e conscientizar 
as pessoas da importância c dos objetivos da Troca Rápida de Ferramentas. Visa estimular o senso crítico e tornar o pessoal conhecedor de uma metodologia de análise e implantação da Troca Rápida de Ferramentas.

Cabe salientar, no entanto, que o nivel educacional do pessoal de chão-de-fábrica é, cm geral, baixo (FLEURY, 1992), o que coloca em dúvida a capacidade de aprendizado de processos de análise do setup c de melhorias viáveis, mesmo com esforços concentrados na simplificação da linguagem e de confecção de materiais mais didáticos. Contudo, pela grande experiência prática, eles têm noçõcs do que pode ser melhorado, embora possam não saber expressar suas idéias de forma adequada. Não podem, portanto, ser deixados à margem do processo, mesmo porque, se houver resistências de sua parte, o processo de implantação pode ser dificultado, já que eles é que trabalharão segundo os novos moldes estabelecidos.

A fim de não criar aversão à novas sistemáticas de trabalho, deve-se fazer com que o pessoal de chão-de-fábrica participe do processo. O ideal seria capacitá-los ou, no mínimo, induzi-los a chegarem nas soluções adequadas, criando-lhes um sentimento de posse sobre estas novas soluções e idéias.

\section{Passo 7. Separar preparação interna de externa}

Deve haver uma separação nílida entre atividades de troca de ferramentas intemas e cxternas. Atividades intcrnas só podem ser realizadas com a máquina parada, e as cxternas devem ser realizadas sempre com a máquina produzindo. Normalmente, as mudanças aqui propostas são de cunlıo comportamental e organizacional, não lavendo necessidade de alterações técnicas profundas. Este passo consiste de três fases específicas: Ievantamento de dados, análise e cxecução prática desta separação.

a) Levantamento de dados: esta fase visa proporcionar o conhecimento detalhado do processo e criar condições para uma boa análise do processo de setup.

b) Análise: a fase de análise visa a separação do setup interno c do externo.

c) Execução: a fase de execução procura garantir que sejam realizadas as preparações internas $\mathrm{c}$ externas conforme ${ }^{\circ}$ planejado.

\section{Passo 8. Simplificar interno e cxterno}

Aqui procura-se simplificar ao máximo todos os aspectos das operações de preparação, tanto internas quanto externas, visando a redução de tempos em ambos os casos. Neste contexto, o principal ponto a ser atacado para a simplificação interna é a climinação dos ajustes, o que exige um estudo mais detalhado de certas etapas do processo de troca de ferramentas.

\section{Passo 9. Transferir interno para externo}

Nesta fasc, coiverte-se as etapas de prepuração intenra $\mathrm{em}$ cxtenă reexaminando-se se não 
restou algum procedimento cxterno que ć rcalizado como interno, c buscando-se soluções tecnológicas para converter cstas ctapas. Faz-se necessária uma análise mais profunda das funções que certas peças $\mathrm{c}$ dispositivos realizam e dos esforços que sofrem, com o objetivo de simplificação ou eliminação de clementos.

Ao final do processo, se não hover a redução sufíciente ou desejada do tempo de setup, deve-se reavaliar e reciecutar os passos cxecutados no nivel operacional. Pode haver a necessidade de reavaliar lambém algumas politicas do nivel tático (passo 4).

Deve-se notar que as clapas 7,8 e 9 podem ser realizadas simultancamente, sem necessidade de real divisão. $\dot{E}$ importante a noção de cada um destes passos, mas, se possivel, sugere-se sua cxecução simultânea, principalmente porque as melhorias realizadas numa ctapa podem ser complementadas ou melhoradas por outras de outra ctapa.

\section{Conclusões}

A sistemálica proposta procura scr genérica. No ciltanto, como cada empresa tem recursos humanos (c seu interrelacionamento), tecnologias $c$ processos característicos, cla pode não ter todos os passos metodológicos e técnicas aplicáveis a todos os casos. Assim, torna-se necessária a adaptação da melodologia de referência a calda caso cm particular. Contudo, esta sistemática permite que sc plancje c organize, de forma lógica c sistematizada, o processo de implanıação.

A sistemálica proposta tem características de planejamento de curto, médio e longo prazos, considera aspectos gerenciais $\mathrm{c}$ administrativos $\mathrm{e}$ busca $o$ desenvolvimento de um ambiente favorável à implantação da Troca Rápida de Ferramentas, permilindo a scleção de recursos c a capacilação das pessoas envolvidas.

A apresentaçĩo da necessidade de cnvolvimento da alta administração, da formação de uma equipe estratégica que realizará todo o plancjamento do proceso de implantação bascando-se na necessidade do cslabclecimento de políticas de atuação, como as propostas neste trabalho, dentre as quais se destacam as politicas de priorização ao ataque $\mathrm{c}$ de formação $\mathrm{c}$ treinamento de equipes, conferem à esta sisıemática as caraclerísticas de médio $\mathrm{c}$ longo prazos necessárias ao desenvolvimento de um ambientc propício à implantação da Troca Rápida de Ferramentas.

No entanto, o sucesso do processo de implantação depende fortemente do cnvolvimento da alta administração $\mathrm{e}$ da capacilação e cooperaçĩo tanto da média gerência quanto do pessoal de chão-de-fábrica. O envolvimento da alta administração é essencial para quebrar barreiras políticas, culturais $\mathrm{c}$ atć financeiras, alćm de promover a aceitação do processo $\mathrm{cm}$ todos os niveis. Sem o envolvimento da alta administração, a implantação global da Troca Rápida de Ferramentas ć inviabilizada, antecipada ou postcriormente. 


\section{Bibliografia}

ANTUNES, J. A.V.; RODRIGUES, L. H. A tcoria das restrições como balizadora das ações visando a troca rápida de ferramentas. Produção, v.3, n.2, p.73-85, 1993.

GOLDRATT, E. M; FOX, R. A corrida pela vantagem competitiva. São Paulo: Educator, IMAM, 1992. 177p.

HALL, R. W. Zcro inventorics. Homcivood: Dow Joncs-Irwin, 1983. 329p. Cap.5, p. 83-118.

HAY, E. J. Just-in-Time. São Paulo: Mallese-Norma, 1992. 233p.
HAYES, R. H. Porque as fábricas japonesas funcionam. Harvard-Exame, Novos Caminhos, Sćric Temática Plancjamcnto Estratćgico, p.88-96, 1990.

FLEURY, A.; HUMPHREY, J. Recursos humanos $\mathrm{c}$ a difusão $\mathrm{c}$ adaptação de novos métodos para a qualidade no Brasil. IPEA, 1992.

SHINGO, S. A revolution in manufacturing: the SMED system. Cambridgc: Productivily Press, 1985. $367 p$.

STALK, G. Time - the next source of competitive advantage. Harvard Business Rewiew, p.41-51, Jul-Aug 1988. 